토끼 간 VX2 암종에서 삼차원 조영증강 초음파를 이용한 종양 부피 측정의 타당성에 대한 이차원 초음파와 조영증강 없는 삼차원 초음파 비교연구: 예비 결과

김지현 ${ }^{1} \cdot$ 김정훈 $^{2,3} \cdot$ 최서연 ${ }^{4} \cdot$ 한준구 $^{2,3}$

${ }^{1}$ 스탠포드대학교 뇌신경연구소, ${ }^{2}$ 서울대학교병원 영상의학과, ${ }^{3}$ 서울대학교 의과대학 방사선연구소, ${ }^{4}$ 순천향대학교 부천병원 영상의학과

\title{
The Feasibility Study of Contrast-enhanced Ultrasound Using a 3 Dimension Transducer for Tumor Volume Measurement in Rabbit Hepatic VX2 Carcinoma Comparison with 2 Dimension Ultrasound and 3 Dimension Ultrasound without Contrast: Preliminary Results
}

\author{
Jeehyun $\mathrm{Kim}^{1}$, Jung Hoon $\mathrm{Kim}^{2,3}$, Seo-Youn Choi ${ }^{4}$, Joon Koo Han ${ }^{2,3}$ \\ 'Department of Neurology and Neurological Sciences, Stanford University Medical Center, Stanford, CA, USA; ${ }^{2}$ Department of Radiology, \\ Seoul National University Hospital, Seoul; ${ }^{3}$ Institute of Radiation Medicine, Seoul National University College of Medicine, Seoul; ${ }^{4}$ Department \\ of Radiology, Soonchunhyang University Bucheon Hospital, Bucheon, Korea
}

Received Sep. 30, 2017

Revised Nov. 23, 2017

Accepted Nov. 24, 2017
Background/Aims: To investigate the feasibility of tumor volume measurement using contrastenhanced ultrasound (US) with 3 dimension transducer (3D CEUS) in rabbit hepatic VX2 carcinoma.

Methods: Three different tumor volume measurements, including 2D US using the equation, 4/3( $\pi$ )(abc), 3D US without contrast, and 3D CEUS were performed in 35 rabbit hepatic VX2 carcinomas. With the tumor volume from computerized tomography (CT) as a reference standard, we compared difference between CT volume and each different US tumor volume. The mean difference and correlation coefficient between each US volume measurement and CT volume were analyzed.

Results: Tumor volume measurement using 3D CEUS and 2D US using equation showed no statistical difference compared to CT volume $\left(0.276 \mathrm{~cm}^{3}, 0.212 \mathrm{~cm}^{3}\right.$, and $0.263 \mathrm{~cm}^{3}$ vs. $0.306 \mathrm{~cm}^{3}$, $0.247 \mathrm{~cm}^{3}, 0.276 \mathrm{~cm}^{3}, P>0.05$ ). However, 3D CEUS provided the highest correlation coefficient with CT volume ( $R=0.835$ and 0.720 ) and the highest intraclass correlation ( 0.973 and 0.993$)$. 3D CEUS provided a smaller mean difference with CT volume $\left(0.016 \mathrm{~cm}^{3}\right.$ and $\left.0.033 \mathrm{~cm}^{3}\right)$ than $2 \mathrm{D}$ US, showing 3D CEUS's accurate measurement of tumor volume.

Conclusions: Due to its highly accurate, reliable, and reproducible measurements of tumor volume, 3D CEUS may be useful for predicting the therapeutic response evaluation after treatment. (J Liver Cancer 2018;18:23-32)

Keywords: Liver cancer; Tumor volume; Ultrasonography

\section{Corresponding author : Jung Hoon Kim}

Department of Radiology, Seoul National University Hospital, 101 Daehak-ro, Jongno-gu, Seoul 03080, Korea 


\section{INTRODUCTION}

Accurate therapeutic response evaluation is important. Tumor size has usually been used in clinical practice to determine the therapeutic response after treatment. World Health Organization (WHO) criteria and Response Evaluation Criteria in Solid Tumors (RECIST) are the most well-known response evaluation methods and both are based on one- or two-dimensional (D) change of tumor size measurement according to radiological images. ${ }^{1,2}$ Recent advances in computerized tomography (CT), magnetic resonance imaging (MRI), and ultrasound (US) volumetric image acquisition allow 3D measurement of tumor volume and provide more accurate assessment of the tumor burden than 2D measurement. It has been reported that tumor volume measurement also provides more accurate information regarding the response after treatment than do 2D measurements. ${ }^{3-5}$

US has had an important role in the monitoring of tumors because of its easy availability, noninvasiveness, convenience, and high accuracy. Recent advances in technology have offered contrast-enhanced US using a 3D transducer (3D CEUS), and which has the theoretical advantage of precise assessment not only of the entire tumor volume but also of tumor enhancement. According to previously published reports, 3D US is accurate and reliable for volume measurements, although most of these have been in vitro studies using variable phantoms. ${ }^{6-9} 3 \mathrm{D}$ CEUS also improved the characterization of focal liver tumors by evaluating their vascular patterns. With the advantages of freedom from ionizing radiation and the easy accessibility of CEUS and 3D techniques, 3D CEUS represents the ideal modality for estimating the entire tumor volume. Because of this advantage, 3D CEUS could potentially be more advantage than 2D US in terms of accurate, reliable, and reproducible measurements of entire tumor volume. However, not much attention has been given to the applications of 3D CEUS for tumor volume measurement.

To the best of our knowledge, there are no previous studies which evaluated the feasibility of tumor volume measurement using 3D CEUS. Therefore, the purpose of this preliminary study is to investigate the feasibility of tumor volume measurement using 3D CEUS in rabbit hepatic VX2 carcinoma com- parison with tumor volume measuring using 2D US with equation and traditional 3D US without contrast enhancement.

\section{METHODS}

This study was approved by our Animal Care and Use Committee. Thirty-five, New Zealand white rabbits, each weighing $3.0-3.5 \mathrm{~kg}$, were used. Rabbit hepatic VX2 carcinoma was conducted using the VX2 carcinoma, maintaining through transplantation of VX2 carcinoma cells into the hind limbs of the rabbits. After administration of intravenous anesthesia using ketamine hydrochloride (Ketamine, Yuhan, $50 \mathrm{mg} / \mathrm{kg}$, Seoul, Korea) and 2\% xylazine (Rompun, Bayer Schering Pharma, $0.1 \mathrm{~mL} / \mathrm{kg}$, Berlin, Germany), the left lobe of the liver was exposed via midline abdominal wall incision. Then a tunnel was made approximately $0.5-1.0 \mathrm{~cm}$ in length in the left lobe using a 20-gauge scalpel needle (Medicut, Ethicon, TX, USA). Approximately a $1-\mathrm{mm}^{3}$ piece of minced fresh VX2 carcinoma was implanted through the tunnel using an ophthalmic nipper, after which gentle pressure using a cotton swab was performed for hemostasis. Using this procedure, a single, well-demarcated hepatic VX2 carcinoma could be created in the left lobe of the liver in each rabbit. 2D US examination was performed on all rabbits two weeks after the VX2 carcinoma implantation and again when the VX2 carcinomas were expected to be round and have a 5- to 10-mm diameter. The tumors were allowed to grow until they reached a size of approximately $7 \mathrm{~mm}+30 \%$. This procedure allowed us to create the model of rabbit hepatic VX2 carcinoma.

\section{Tumor volume measurement using US}

Thirty-five, rabbit hepatic VX2 carcinomas were included in this study. Fig. 1 shows an overview of the experimental design. Initial US examination was performed at the tumor size of approximately $7 \mathrm{~mm}+30 \%$ and the follow-up US examination was performed one-day after the baseline US examination by a radiologist (JH Kim) using an US unit (Aplio 500; Toshiba Medical, Otawara, Japan) with PLT-1204BT with a 12 $\mathrm{MHz}$, center-frequency, linear 2D-transducer and PLT-1204 MV with a $12-\mathrm{MHz}$, center-frequency, mechanical 3D-transducer 


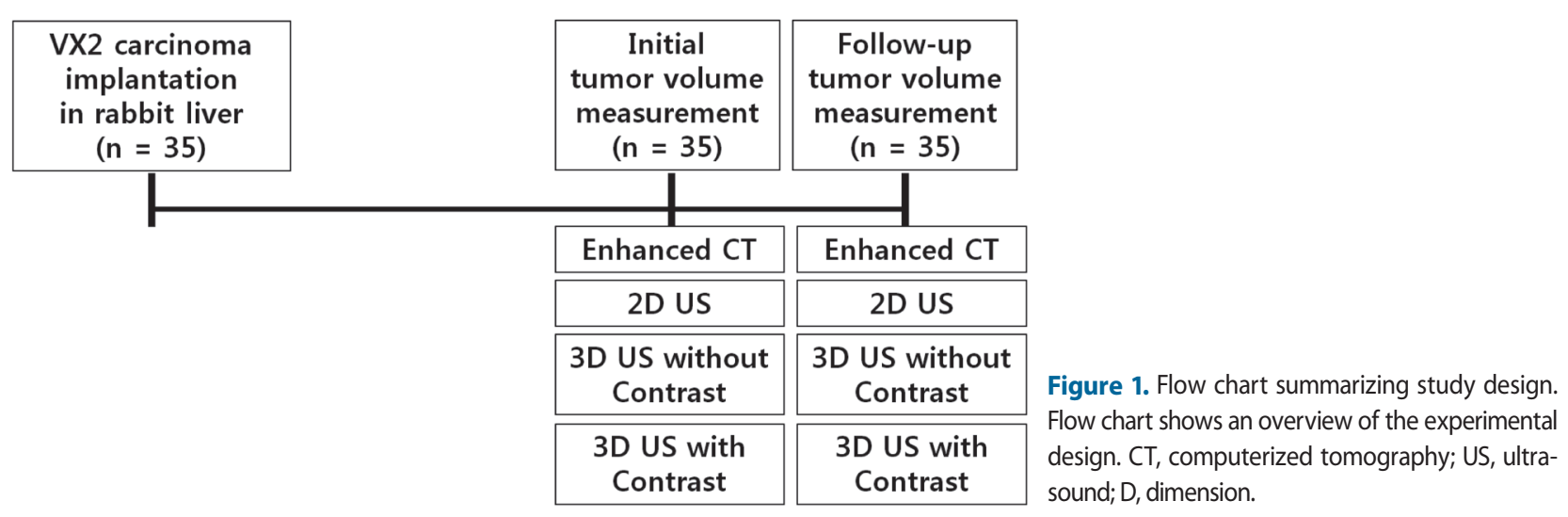

with the following parameters: a dynamic range of $65 \mathrm{~dB}$; a gain of $83 \mathrm{~dB}$; a frame rate of $5 \mathrm{fps}$; and a depth of $2.5 \mathrm{~cm}$ in the 2D-transducer, a dynamic range of $65 \mathrm{~dB}$; a gain of $80 \mathrm{~dB}$; a frame rate of $5 \mathrm{fps}$; and a depth of $2.5 \mathrm{~cm}$ in the 3D-transducer.

Three different tumor volumes, including the calculated tumor volume obtained on 2D US using the equation for a 3D ellipsoid model, $4 / 3(\pi)(a b c)$, where $a, b$, and $c$ are the distances from the center to the edge of each axis on the 2D US; tumor volume from 3D US without contrast; and tumor volume from 3D US with contrast (3D CEUS) were obtained. For the tumor volume from 2D using the equation, a morphological study was performed in the B mode in order to identify the tumor. The tumor was then imaged using the maximum transverse planes, which were measured accordingly. Tumor volume from 2D US using the equation measured three different diameters of the tumor using two different planes. Tumor volume from 3D US without contrast was measured by drawing the region of interest (ROI) along the tumor margin using eight different $2 \mathrm{D}$ planes. The tumor was imaged using the maximum transverse planes. The probe held by the radiologist automatically swept the region in the volume of interest (VOI) in which the tumor size and position were already adjusted on the grey-scale US in order to contain the target tumor. The sweeping angles were set at $20^{\circ}$ throughout the study. Volumetric measurements were done using the analysis software in the US unit. The software allowed simultaneous display in three 2D perpendicular planes. One 2D plane was selected, and the outer boundary of the tumor was manually drawn on the selected 2D image, after which the volume data were rotated on the rotation axis by $22.5^{\circ}$ to produce the next
$2 \mathrm{D}$ image. Because each rotation step was $22.5^{\circ}$, each measurement required eight rotation steps, and thus manual drawing of the boundaries on 2D images was performed a total of eight times.

3D CEUS was performed initially and on a one-day followup examination by a radiologist (JH Kim) using the same US unit (Aplio 500; Toshiba Medical, Otawara, Japan) and with a $12-\mathrm{MHz}$, center-frequency, mechanical 3D-transducer (PLT$1204 \mathrm{MV}$ ) involving the following parameters: a dynamic range of $40 \mathrm{~dB}$; a mechanical index of 0.08 ; a gain of $75 \mathrm{~dB}$; and a frame rate of 5 fps. For 3D CEUS, we first attempted to identify the tumor in the B mode using a mechanical 3D transducer. Then, we performed 3D CEUS in the contrast harmonic image mode (CHI, Toshiba Medical Systems, Otawara, Japan) using a 3D transducer after intravenous injection of $1 \mathrm{~mL}$ of the contrast agent, sulfur hexafluoride-filled microbubbles (SonoVue; Bracco, Milan, Italy), through an ear vein. 3D CEUS examinations were recorded from the beginning of the contrast injection and continued for 90 seconds. Using this 3D CEUS image data, the tumor volume seen on 3D CEUS was measured by drawing the ROI along the tumor margin using two, different planes after contrast enhancement. All tumor volume measurements using US were performed twice, after which the mean value was obtained. Fig. 2 demonstrates the three different methods of tumor volume measurement.

\section{CT volume measurement}

Contrast-enhanced CT was performed initially and on the one-day, follow-up examination. After anesthesia was admin- 

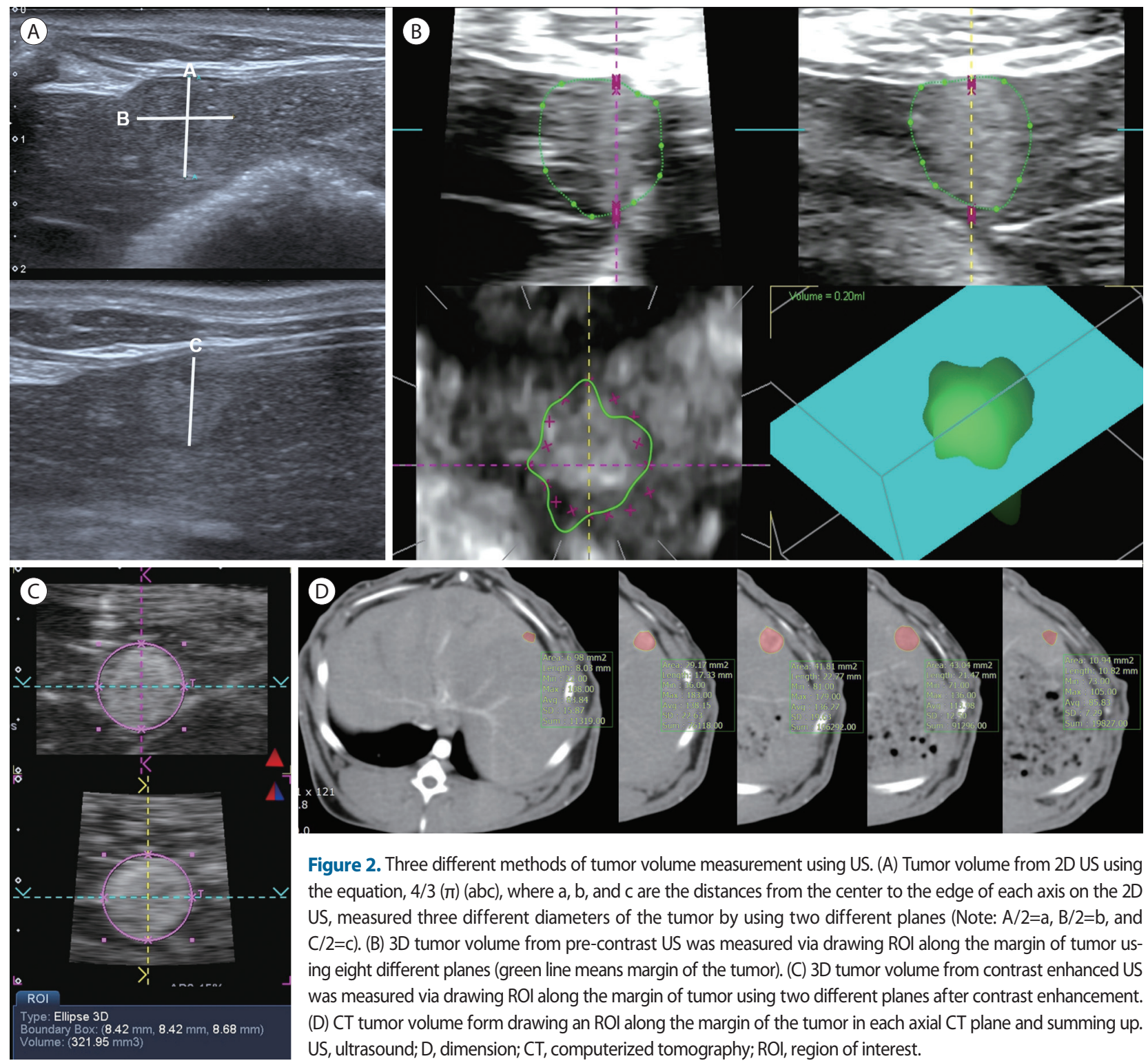

Figure 2. Three different methods of tumor volume measurement using US. (A) Tumor volume from 2D US using the equation, $4 / 3(\pi)(a b c)$, where $a, b$, and $c$ are the distances from the center to the edge of each axis on the 2D US, measured three different diameters of the tumor by using two different planes (Note: $A / 2=a, B / 2=b$, and $\mathrm{C} / 2=\mathrm{C}$ ). (B) $3 \mathrm{D}$ tumor volume from pre-contrast US was measured via drawing $\mathrm{ROI}$ along the margin of tumor using eight different planes (green line means margin of the tumor). (C) 3D tumor volume from contrast enhanced US was measured via drawing ROI along the margin of tumor using two different planes after contrast enhancement. (D) CT tumor volume form drawing an ROI along the margin of the tumor in each axial CT plane and summing up. US, ultrasound; D, dimension; $\mathrm{CT}$, computerized tomography; ROI, region of interest.

istered using an intramuscular injection of ketamine hydrochloride ( $50 \mathrm{mg} / \mathrm{kg}$ body weight), each rabbit was attached to a board in the supine position, and an abdominal bandage was applied tightly in order to minimize movement artifacts. A 24-gauge scalpel (Medicut, Ethicon) was inserted into the auricular vein. Scanning was performed using an MDCT unit (Discovery CT750 HD scanner, GE Healthcare, Milwaukee, WI, USA). In order to determine the tumor location, unenhanced CT was performed of the entire liver (detector configuration, $64 \times 0.625 \mathrm{~mm} ; 2.5 \mathrm{~mm} / 2.5 \mathrm{~mm}$ slice thickness and interval for axial images; $1.375 \mathrm{pitch} ; 0.4 \mathrm{~s}$ tube rotation time).
CT was performed five seconds following IV bolus injection of contrast material (iopromide, Ultravist 370, Bayer Schering Pharma, Berlin, Germany) and continued for 60 seconds. The contrast material was injected through the auricular vein using a power injector (Empower CTA Dual Injector, E-Z-EM) for 5 seconds at a rate of $1 \mathrm{~mL} / \mathrm{s}$. The Perfusion CT parameters were as follows: cine mode scan with 0.4 second per $360^{\circ}$ rotation; $120 \mathrm{kVp}$; effective tube current-exposure time product, $150 \mathrm{mAs}$; detector configuration, $64 \times 0.625 \mathrm{~mm}$; and field of view, $12 \mathrm{~cm}^{2}$. The CT scans were reconstructed using the following parameters: slice thickness, $2.5 \mathrm{~mm}$; no gap; matrix 
size, $512 \times 512$; and temporal resolution, 0.4 second. The reconstructed image data were transferred to an imaging workstation (Advantage Windows 4.5, GE Healthcare, WI, USA) for tumor volume measurement. All CT tumor volume measurements were performed by a radiologist (JK Han). One radiologist (JK Han) drew an ROI along the margin of the tumor in each plane twice, after which the mean value was then obtained. With the tumor volume from MDCT as a reference standard, the difference between CT volume and each different US tumor volume was compared.

\section{Statistical analysis}

The differences in the tumor volume were assessed using the paired T-test. Wilcoxon's signed rank test with Bonferroni's correction was used to assess the difference between each of the US volume measurements and the CT volume. The mean difference and the correlation of each measurement method were assessed using the Bland-Altman plot and the intraclass correlation coefficient. The linear regression analysis was calculated for the evaluation of the correlation between each US volume measurement and the CT volume. A $P$-value less than 0.05 was considered to indicate a statistically significant difference. Statistical analyses were performed using an SPSS software package (version 14.0, IBM Corp., Armonk, NY, USA) for Windows (Microsoft, Redmond, WA, USA) and MedCalc for Windows, version 9.6.4.0 (MedCalc Software, Mariakerke, Belgium).

\section{RESULTS}

Tumor volume from 3D CEUS showed no statistical difference to the tumor volume measured using MDCT (Median [Interquartile Range]); $0.276 \mathrm{~cm}^{3}(0.196-0.398)$ vs. $0.263 \mathrm{~cm}^{3}$ (0.204-0.356), $P=0.081$ on the initial measurement; and 0.306 $\mathrm{cm}^{3}(0.202-0.446)$ vs. $0.276 \mathrm{~cm}^{3}(0.214-0.394), P=0.053$ on the follow-up measurement). Tumor volume from 2D US using the equation also showed no significant difference to the tumor volume measured by MDCT $(P>0.05)$. In the initial tumor volume, the CT volume was $0.263 \mathrm{~cm}^{3}$ (0.204-0.356), 2D US from equation was $0.212 \mathrm{~cm}^{3}(0.159-0.306)$, 3D US without contrast was $0.21 \mathrm{~cm}^{3}(0.15-0.285)$, and 3D US with contrast was $0.276 \mathrm{~cm}^{3}(0.196-0.398)$. In the follow-up tumor volume measurement, the CT volume was $0.276 \mathrm{~cm}^{3}(0.214-$ $0.394), 2 \mathrm{D}$ US from equation was $0.247 \mathrm{~cm}^{3}(0.166-0.348)$, 3D US without contrast was $0.23 \mathrm{~cm}^{3}(0.18-0.295)$, and 3D US with contrast was $0.306 \mathrm{~cm}^{3}(0.202-0.446)$. Each measurement method showed a strong intraclass correlation; although 3D US with contrast provided the highest intraclass correlation ( 0.973 on the baseline and 0.993 on the follow-up measurement). Table 1 summarizes the accuracy of the different US tumor volume measurements using CT tumor volume measurement in the initial and follow-up examinations.

Both the tumor volume measured by 3D CEUS and 2D US from equation showed no significant median difference compared with the CT volume. However, 3D CEUS provided the highest correlation coefficient with the CT volume $(\mathrm{R}=0.835$ and 0.72 , Fig. 3). Table 2 summarizes the median difference

Table 1. Comparison of the accuracy of different US tumor volume measurements with CT volume measurement in the initial and follow up examinations

\begin{tabular}{|c|c|c|c|c|c|c|}
\hline Tumor volume measurement & Baseline $(n=35)$ & ICC & $P$-value & Follow up $(n=35)$ & ICC & $P$-value \\
\hline CT volume $\left(\mathrm{cm}^{3}\right)$ & $0.263(0.204-0.356)$ & 0.976 & $P=0.081^{*}$ & $0.276(0.214-0.394)$ & 0.991 & $P=0.291^{*}$ \\
\hline $2 \mathrm{D}$ US from 4/3(л) $(\mathrm{abc})\left(\mathrm{cm}^{3}\right)$ & $0.212(0.159-0.306)$ & 0.945 & $P=0.000^{\dagger}$ & $0.247(0.166-0.348)$ & 0.971 & $P=0.000^{\dagger}$ \\
\hline 3D US without contrast $\left(\mathrm{cm}^{3}\right)$ & $0.21(0.15-0.285)$ & 0.870 & \multirow[t]{2}{*}{$P=0.069^{\ddagger}$} & $0.23(0.18-0.295)$ & 0.900 & \multirow[t]{2}{*}{$P=0.053^{\ddagger}$} \\
\hline 3D US with contrast $\left(\mathrm{cm}^{3}\right)$ & $0.276(0.196-0.398)$ & 0.973 & & $0.306(0.202-0.446)$ & 0.993 & \\
\hline
\end{tabular}

Values are expressed as median (interquartile range).

US, ultrasound; CT, computerized tomography; D, dimension; ICC, intraclass correlation.

${ }^{*} P$-value between CT voloume and $2 \mathrm{D} U \mathrm{US}^{\dagger}{ }^{\dagger}$-value between $\mathrm{CT}$ voloume and $3 \mathrm{D}$ US without contrast; ${ }^{\ddagger} P$-value between $\mathrm{CT}$ voloume and $3 \mathrm{D}$ US with contrast. 


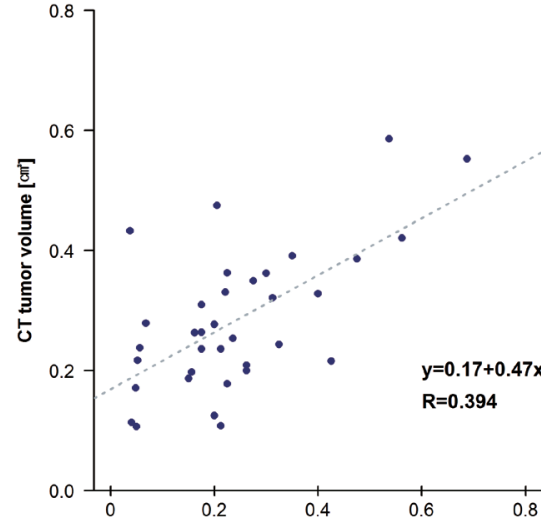

(A)

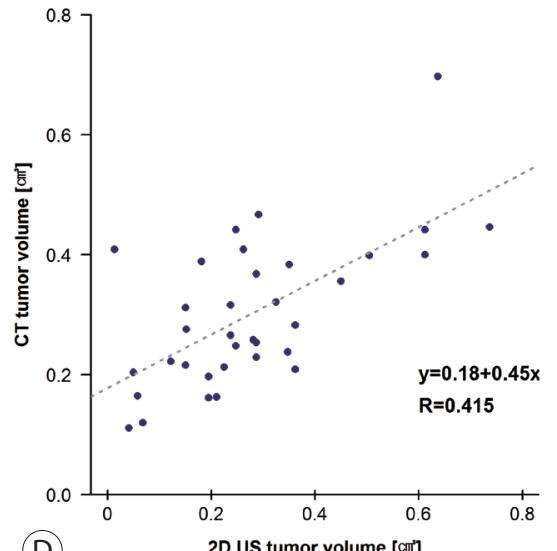

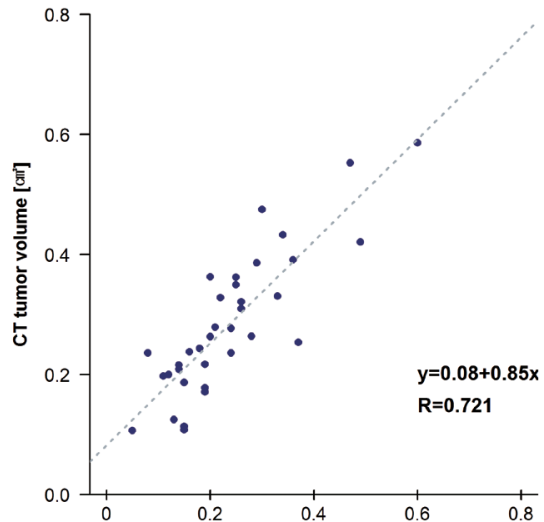

(B) 3D us woC tumor volume [ $\left.\mathrm{Cm}^{\mathrm{m}}\right]$

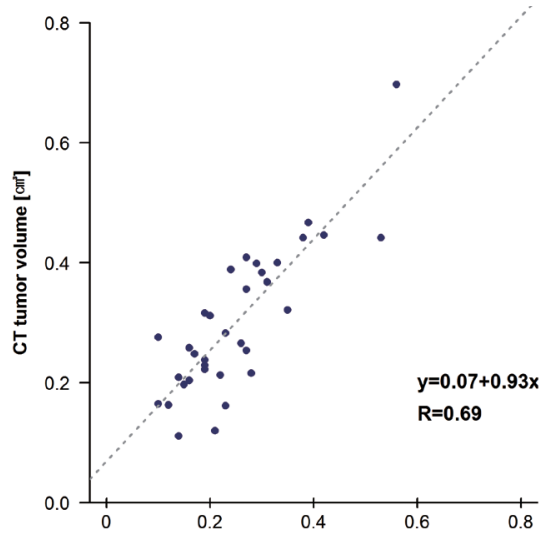

(E) 3D us woC tumor volume [omi]

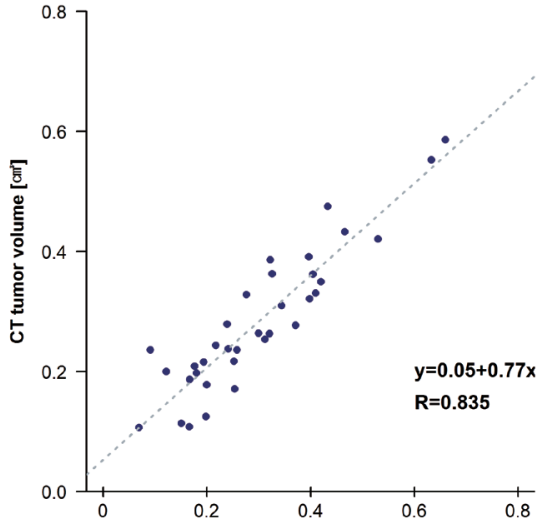

(C) 3D us wC tumor volume [cm']

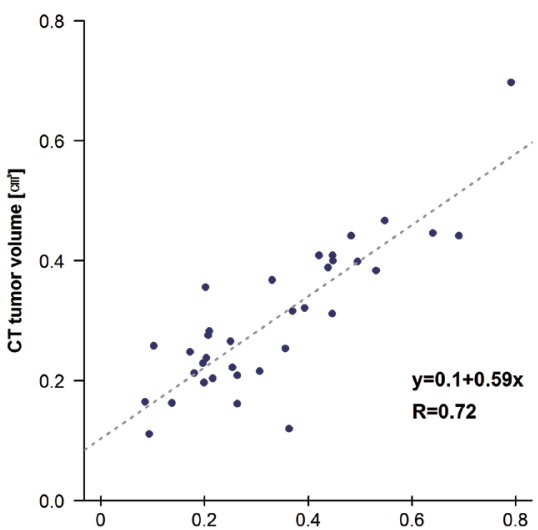

(F) 3D us wC tumor volume [cmi']

Figure 3. Comparison of the linear regression analyses of different US tumor volume measurements with $\mathrm{CT}$ volume measurement in the initial (A-C) and follow up examinations (D-F). (A-C) Initial examinations. (D-F) Follow up examinations. US, ultrasound; D, dimension; CT, computerized tomography; wC, with contrast; woC, without contrast.

Table 2. Comparison of the median difference and correlation coefficient between different US tumor volume measurements and CT volume measurement in the baseline and follow-up examinations

\begin{tabular}{|c|c|c|c|c|c|c|c|c|}
\hline \multirow[b]{2}{*}{$\begin{array}{l}\text { Comparison with tumor } \\
\text { volume measurement }\end{array}$} & \multicolumn{4}{|c|}{ Initial $(n=35)$} & \multicolumn{4}{|c|}{ Follow up $(n=35)$} \\
\hline & $\begin{array}{l}\text { Median } \\
\text { difference } \\
\left(\mathrm{cm}^{3}\right)\end{array}$ & IQR & $P$-value* & $\begin{array}{l}\text { Correlation } \\
\text { (R) }\end{array}$ & $\begin{array}{c}\text { Median } \\
\text { difference } \\
\left(\mathrm{cm}^{3}\right)\end{array}$ & IQR & $P$-value* & $\begin{array}{l}\text { Correlation } \\
\text { (R) }\end{array}$ \\
\hline $\begin{array}{l}\text { 2D US from 4/3( } \pi) \\
(\mathrm{abc})-\mathrm{CT} \text { volume }\left(\mathrm{cm}^{3}\right)\end{array}$ & -0.049 & $(-0.106,0.058)$ & 0.081 & 0.394 & -0.029 & $(-0.104,0.052)$ & 0.295 & 0.415 \\
\hline $\begin{array}{l}\text { 3D US without contrast } \\
(\mathrm{cm} 3)-C T \text { volume }\left(\mathrm{cm}^{3}\right)\end{array}$ & -0.061 & $(-0.086,0.004)$ & $<0.001$ & 0.721 & -0.058 & $(-0.092,-0.016)$ & $<0.001$ & 0.69 \\
\hline $\begin{array}{l}\text { 3D US with contrast } \\
\left(\mathrm{cm}^{3}\right)-C T \text { volume }\left(\mathrm{cm}^{3}\right)\end{array}$ & 0.033 & $(-0.03,0.064)$ & 0.069 & 0.835 & 0.038 & $(-0.032,0.092)$ & 0.053 & 0.72 \\
\hline
\end{tabular}

US, ultrasound; CT, computerized tomography; IQR, inter quartile range; $D$, dimension.

${ }^{*} P$-values were calculated by multiple Wilcoxon's signed rank test with Bonferroni's correction.

and the correlation coefficient between different US tumor volume measurements and $\mathrm{CT}$ tumor volume measurement in the initial and follow-up examinations. The Bland-Altman plot depicted the mean difference between the 3D CEUS and the CT volumes. The mean difference was $0.016 \mathrm{~cm}^{3}$ ( $\operatorname{stan}$ dard deviation $[\mathrm{SD}], \pm 1.96$, Fig $4 \mathrm{~A}-\mathrm{C})$ in the initial exami- 

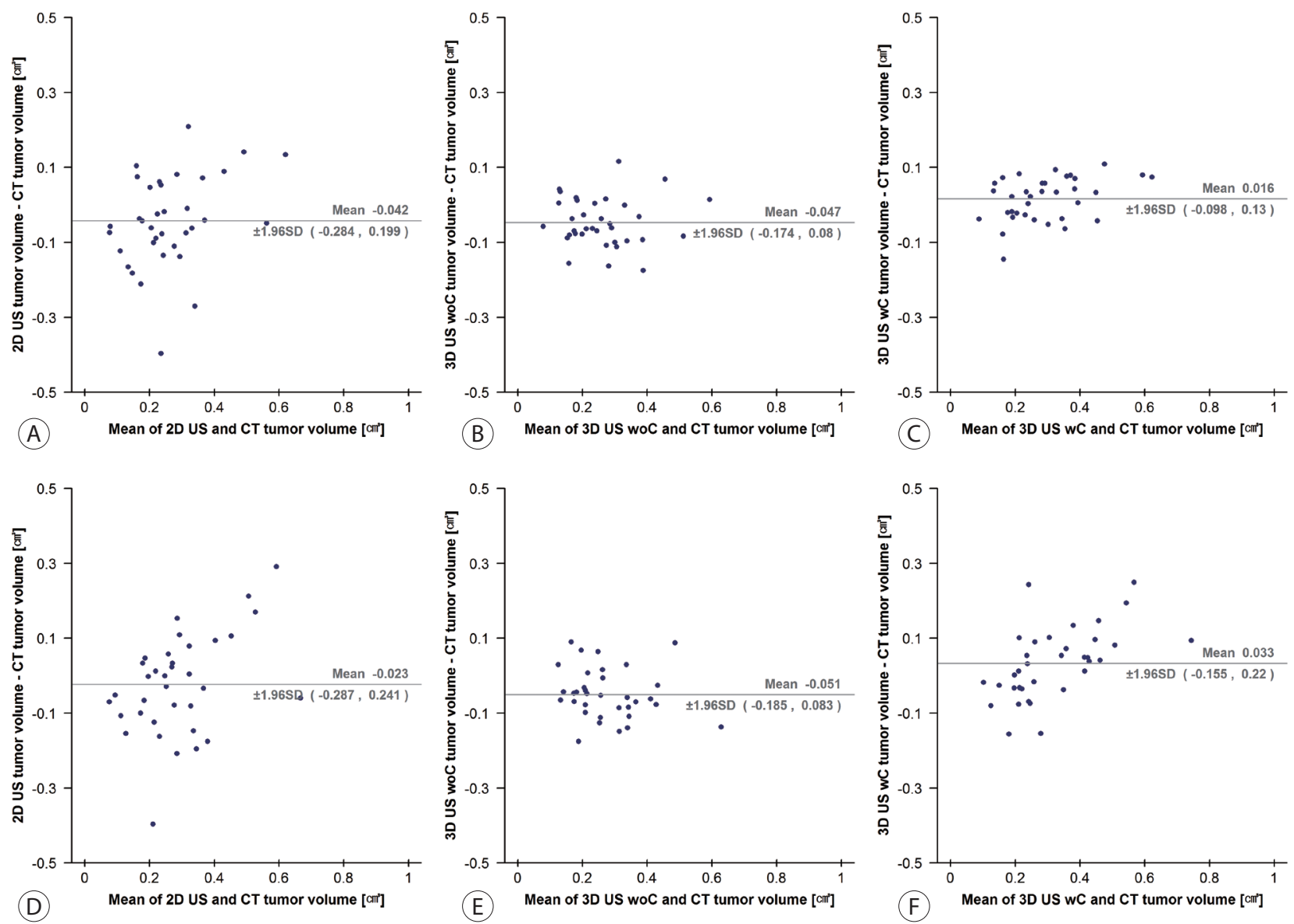

Figure 4. Comparison of the Bland-Altman plots of different US tumor volume measurements with CT volume measurement in the initial (A-C) and follow up examinations (D-F). (A-C). Initial examinations. (D-F) Follow up examinations. US, ultrasound; D, dimension; CT, computerized tomography; wC, with contrast; woC, without contrast; $\mathrm{SD}$, standard deviation.

nations and $0.033 \mathrm{~cm} 3(\mathrm{SD}, \pm 1.96$, Fig. 4D-F) in the follow-up examinations. The difference between 2D US from equation and the CT volume was $-0.042 \mathrm{~cm}^{3}(\mathrm{SD}, \pm 1.96)$ in the initial examinations and $-0.023 \mathrm{~cm}^{3}(\mathrm{SD}, \pm 1.96)$ in the follow-up examinations. The mean difference between 3D US without contrast and the CT volume was $-0.047 \mathrm{~cm}^{3}(\mathrm{SD}, \pm 1.96)$ in the initial examinations and $-0.051 \mathrm{~cm}^{3}(\mathrm{SD}, \pm 1.96)$ in the followup examinations. As shown in Fig. 4, 3D CEUS provided a small mean difference compared with the CT volume.

\section{DISCUSSION}

This study found that tumor volume measurement from 3D CEUS and 2D US using equation showed no statistical difference to the tumor volume measured using. However, 3D CEUS provided the highest correlation coefficient with the CT volume as well as the highest intraclass correlation. 3D CEUS also provided a relatively small mean difference with that of the CT volume. The mean difference was $0.016 \mathrm{~cm}^{3}$ in the initial examinations and $0.033 \mathrm{~cm}^{3}$ on the follow-up examinations. Although 2D US from equation and 3D US without contrast had a tendency to underestimate the tumor volume, tumor volume measured using 3D CEUS had a tendency to overestimate the tumor volume.

Highly accurate, reliable, and reproducible measurements of tumor volume are important as any variation of tumor volume on follow-up images caused by measurement errors might be considered as a true response or non-response to a patient's therapy. CT is currently considered as a method of reference standard for tumor volume measurement. ${ }^{3-5,10-12}$ 
However, its ionizing radiation and the risk of contrast reaction limit its application. With the advantages of its accessibility, no ionizing radiation, and a low risk of side reaction to contrast, US is currently considered the ideal imaging tool for tumor volume measurement. This study results showed that tumor volume measurement using 3D CEUS had no statistically significant difference with the CT volume $(P>0.05)$. 3D CEUS has only recently been introduced. According to previously published reports, 3D CEUS improved the detection rate of tumor vascularity. ${ }^{6-9}$ Luo et al. found that $3 \mathrm{D}$ CEUS was useful for characterizing focal liver tumors. In their study, 3D CEUS provided a sensitivity of $92 \%$, specificity of $91 \%$ for hepatocellular carcinoma, $84 \%, 97 \%$ for metastases, $91 \%$, 98\% for hemangiomas, and 80\%, 99\% for FNHs and with good to excellent inter-reader agreement. ${ }^{13}$ Additionally, these study results showed no significant difference in the diagnosis accuracy between 3D CEUS and 2D CEUS, further suggesting that the spatial resolution of the current 3D probes may be limited. ${ }^{13}$

This study results showed that tumor volume measurement using 2D US and equation had no statistical difference with that of the CT volume $(P>0.05)$. The tumor volume estimated using 2D US by simple formulae are generally useful for the evaluation of regular shaped tumors. According to previously published reports, volume measurement from equation is reliable and valid for a round and regular object such as a balloon or phantoms. ${ }^{5,14}$ In this study, as the rabbit hepatic VX2 carcinoma model usually provided a round and regularly shaped tumor model, it demonstrated that tumor volume measurement using the 2D US equation showed no statistically significant difference to that of the CT volume. However, liver tumors are often irregularly shaped, and 2D US has limitations in such conditions. In this study, 2D US showed a lower intraclass correlation ( 0.945 and 0.971$)$ than 3D CEUS (0.973 and 0.993). 2D US also provided a lower correlation coefficient compared with CT volume ( $\mathrm{R}=0.394$ and 0.415$)$, than $3 \mathrm{D}$ CEUS ( $\mathrm{R}=0.835$ and 0.72 ). This might be caused by the fact that no contrast was used during 2D US examinations; therefore, making it difficult to define exact tumor margins. However, 3D CEUS could easily detect a tumor margin because of the use of contrast.
Theoretically, tumor volume measured using 3D US is accurate and reliable for volume measurements using multiple image planes. It has been reported that the volumetric measurements using 3D US are accurate in both regular and irregularly shaped structures. ${ }^{15-17}$ However, most of the previously published reports used the phantoms for the evaluation of the accuracy of 3D volume measurement. ${ }^{18,19}$ Precise drawing of the outline of the tumor boundaries is important for accurate and reliable tumor volume measurement, although 3D US without contrast produced an unclear outline of the tumor boundaries in some planes. Because this study was used manually drawing the tumor outlines, measurement error was also possible, especially for objects that showed an indistinct margin from the background, as they are difficult to draw the exact tumor margin. Quivey et al. reported that follow up 3D CT volume analysis was an accurate $( \pm 5 \%)$ and reproducible technique for the evaluation of pancreatic cancer. ${ }^{20}$

This study had some limitations. First, this study was used CT volume as a reference standard. Although CT is currently considered as a method of reference standard for tumor volume measurement, it also has possibility of measurement errors. However, in an in vivo study it is difficult to have accurate reference standard. In addition, US tumor volume measurement requires manual delineation of the tumor borders, which causes an inevitable measurement error. To reduce the measurement error in this study, all tumor volume measurements were performed twice, after which the mean value was obtained. Second, owing to recent technical advances, the clinical application of 3D US has been increased, however, 3D US still has some limitations, one of which is that it is difficult to trace the tumor margin without contrast enhancement, especially in some tumors with ill-defined margins. For this reason, in this study the 3D tumor volume from contrast-enhanced US was shown to be more accurate than the $3 \mathrm{D}$ tumor volume measurement without contrast. Third, this study was used two different 2D and 3D transducers. They have different gain levels for optimal image qualities. So this study was used different gain between linear 2D-transducer and mechanical 3Dtransducer. However, we believe, it did not make significant effect to this results.

Accurate and reliable tumor volume measurement is very 
important in order to achieve optimal therapeutic decisions. Because of the accessibility, no ionizing radiation, and the low risk of side reactions to contrast, 3D CEUS is considered the ideal imaging tool for tumor volume measurement. In conclusion, 3D CEUS has been shown to accurately measure tumor volume. In addition, 3D CEUS provided the highest intraclass correlation, the highest correlation coefficient, and a relatively small mean difference with the CT tumor volume, compared to other techniques. Therefore, 3D CEUS may be feasible for predicting the therapeutic response evaluation after treatment due to its highly accurate, reliable, and reproducible measurements of the tumor volume.

\section{ETHICAL STATEMENTS}

All institutional and national guidelines for the care and use of laboratory animals were followed. This study was approved by our Animal Care and Use Committee (IACUC No: 130230-COA2).

\section{AUTHOR CONTRIBUTIONS}

JH Kim designed the study, analyzed data, and finally approved the version to be published. J Kim, JH Kim, JK Han contributed equally to performing experiments, J Kim wrote the paper, SY Choi analyzed data, JK Han contributed equally to approve the final version to be published.

\section{ACKNOWLEDGEMENT}

This study was supported by an academic research fund of the Korean Liver Cancer Study for 2017.

This research was supported by Basic Science Research Program through the National Research Foundation of Korea (NRF) funded by the Ministry of Science, ICT \& Future Planning (2017R1A2B4004951) and we would like to thank Toshiba Medical Systems for technical support.

\section{Conflicts of Interest}

No conflict of interest is declared by the authors.

\section{REFERENCES}

1. Eisenhauer EA, Therasse P, Bogaerts J, Schwartz LH, Sargent D, Ford $R$, et al. New response evaluation criteria in solid tumours: revised RECIST guideline (version 1.1). Eur J Cancer 2009;45:228-247.

2. Gonzalez-Guindalini FD, Botelho MP, Harmath $C B$, Sandrasegaran K, Miller FH, Salem R, et al. Assessment of liver tumor response to therapy: role of quantitative imaging. Radiographics 2013;33:17811800.

3. Buckler AJ, Mulshine JL, Gottlieb R, Zhao B, Mozley PD, Schwartz L. The use of volumetric $\mathrm{CT}$ as an imaging biomarker in lung cancer. Acad Radiol 2010;17:100-106.

4. Chalian H, Tochetto SM, Töre HG, Rezai P, Yaghmai V. Hepatic tumors: region-of-interest versus volumetric analysis for quantification of attenuation at CT. Radiology 2012;262:853-861.

5. Keil S, Plumhans C, Behrendt FF, Stanzel S, Suehling M, Mühlenbruch $\mathrm{G}$, et al. Semi-automated quantification of hepatic lesions in a phantom. Invest Radiol 2009;44:82-88.

6. Leen E, Kumar S, Khan SA, Low G, Ong KO, Tait P, et al. Contrastenhanced 3D ultrasound in the radiofrequency ablation of liver tumors. World J Gastroenterol 2009;15:289-299.

7. Luo W, Numata K, Morimoto M, Nozaki A, Nagano Y, Sugimori K, et al. Three-dimensional contrast-enhanced sonography of vascular patterns of focal liver tumors: pilot study of visualization methods. AJR Am J Roentgenol 2009;192:165-173.

8. Luo W, Numata K, Morimoto M, Oshima T, Ueda M, Okada M, et al. Role of Sonazoid-enhanced three-dimensional ultrasonography in the evaluation of percutaneous radiofrequency ablation of hepatocellular carcinoma. Eur J Radiol 2010;75:91-97.

9. Xu HX, Lu MD, Xie XH, Xie XY, Xu ZF, Chen LD, et al. Three-dimensional contrast-enhanced ultrasound of the liver: experience of 92 cases. Ultrasonics 2009;49:377-385.

10. Galizia MS, Töre HG, Chalian H, McCarthy R, Salem R, Yaghmai V. $M D C T$ necrosis quantification in the assessment of hepatocellular carcinoma response to yttrium 90 radioembolization therapy: comparison of two-dimensional and volumetric techniques. Acad Radiol 2012;19:48-54.

11. Lee SM, Kim SH, Lee JM, Im SA, Bang YJ, Kim WH, et al. Usefulness of $\mathrm{CT}$ volumetry for primary gastric lesions in predicting pathologic response to neoadjuvant chemotherapy in advanced gastric cancer. Abdom Imaging 2009;34:430-440.

12. Singh AK, Hiroyuki Y, Sahani DV. Advanced postprocessing and the emerging role of computer-aided detection. Radiol Clin North Am 2009;47:59-77.

13. Luo W, Numata K, Morimoto M, Kondo M, Takebayashi S, Okada $M$, et al. Focal liver tumors: characterization with 3D perflubutane microbubble contrast agent-enhanced US versus 3D contrastenhanced multidetector CT. Radiology 2009;251:287-295. 
14. Rkein AM, Harrigal C, Friedman AC, Persky D, Krupinski E. Comparison of the accuracy of $\mathrm{CT}$ volume calculated by circumscription to prolate ellipsoid volume (bidimensional measurement multiplied by coronal long axis). Acad Radiol 2009;16:181-186.

15. Kot BC, Sin DM, Ying M. Evaluation of the accuracy and reliability of two 3-dimensional sonography methods in volume measurement of small structures: an in vitro phantom study. J Clin Ultrasound 2009;37:82-88.

16. Pang BS, Kot BC, Ying M. Three-dimensional ultrasound volumetric measurements: is the largest number of image planes necessary for outlining the region-of-interest? Ultrasound Med Biol 2006;32:1193-1202.

17. $X u H X$, Yin $X Y$, Lu MD, Liu GJ, Xu ZF. Estimation of liver tumor volume using a three-dimensional ultrasound volumetric system. Ultrasound Med Biol 2003;29:839-846.

18. Park SH, Choi BI, Han JK, Yoon CJ, Lee JW, Kim SS, et al. Volumetric tumor measurement using three-dimensional ultrasound: in vitro phantom study on measurement accuracy under various scanning conditions. Ultrasound Med Biol 2004;30:27-34.

19. Raine-Fenning NJ, Clewes JS, Kendall NR, Bunkheila AK, Campbell $B K$, Johnson IR. The interobserver reliability and validity of volume calculation from three-dimensional ultrasound datasets in the in vitro setting. Ultrasound Obstet Gynecol 2003;21:283-291.

20. Quivey JM, Castro JR, Chen GT, Moss A, Marks WM. Computerized tomography in the quantitative assessment of tumour response. $\mathrm{Br}$ J Cancer Suppl 1980;4:30-34. 